\title{
Expression and clinical significance of matrix metalloproteinase 9 (MMP9) papillary thyroid carcinomas
}

\author{
Xianying Meng ${ }^{1}$, Tebo Hua ${ }^{1}$, Qiang Zhang ${ }^{1}$, Renzhu Pang ${ }^{1}$, Guibin Zheng ${ }^{1}$ and Dong Song ${ }^{2 *}$ \\ ${ }^{1}$ Department of Thyroid Surgery, The First Affiliated Hospital of Jilin University, Changchun, Jilin 130021, China. \\ ${ }^{2}$ Department of Thyroid and Breast Surgery, The First Affiliated Hospital of Jilin University, \\ Changchun, Jilin 130021, China.
}

Accepted 23 August, 2012

\begin{abstract}
Matrix metalloproteinases (MMPs) play a crucial role in tumor invasion and metastasis. There have been only a few studies on the MMP expression in thyroid carcinomas. Therefore, we investigated the MMP9 expression in 66 papillary thyroid carcinomas (PTC) using immunohistochemistry and quantitative reverse transcription-polymerase chain reaction (qRT-PCR) on protein level and mRNA level, respectively. We also examined the correlations between the immunohistochemical scores and several clinicopathological parameters. The results demonstrated that MMP9 was significantly up-regulated in cancer tissue in comparison to begnin thyoid tumor tissue on mRNA level $(P<0.05)$. On protein level, MMP9 was also highly increased in cancer tissue in comparison to begnin thyoid tumor. It is found that high expression MMP9 proteins significantly correlated with large tumor size, presence of lymph node metastasis, Union Internationale Control Cancer (UICC) stage. These data suggest that MMP9 proteins are increased in tumors cells of PTC and that it plays an important role in the invasion and metastasis of PTC.
\end{abstract}

Key words: Thyroid carcinomas, matrix metalloproteinase 9 (MMP9), quantitative reverse transcriptionpolymerase chain reaction (qRT-PCR), immunohistochemistry, papillary thyroid carcinomas.

\section{INTRODUCTION}

Thyroid carcinoma is the most common malignancy of the endocrine system and accounts for approximately $1 \%$ of all newly diagnosed cancer (Guang et al, 2011., Chen et al., 2011; Hundahl et al., 2000; Roskies et al., 2012). Thyroid cancer can be divided into papillary thyroid carcinomas (PTC), follicular, medullary, or anaplastic histological types. PTC is the most common type of thyroid cancer and accounts for more than $83 \%$ of all thyroid malignancies (Brown et al., 2011; Dal Maso et al., 2009). Hence, it is important to understand molecular mechanisms responsible for PTC development, progression and metastasis, and in turn, develop novel strategies for the early detection, prevention, and treatment of thyroid cancer.

\footnotetext{
*Corresponding author. E-mail: songdong258@yahoo.cn.
}

Tumor invasion is a cascade of sequential events that involves detachment of malignant cells from their site of origin and invasion through the surrounding stroma into lymphovascular channels (Hagemann et al., 2012). All these steps are associated with extracellular matrix (ECM) degradation, and the proteolytic breakdown of major ECM components requires specific proteases. Matrix metalloproteinases (MMPs) are proteolytic enzymes that degrade ECM components at neutral $\mathrm{pH}$ (Salamonsen et al., 1996; Chambers et al., 1997). Numerous studies have demonstrated that individual MMPs play crucial roles in tumor invasion and metastasis (Parson et al., 1997; Westermarck et al., 1999; Curran et al., 1997; Yu et al, 2012). Expression of MMP-2 is considered especially important as an indicator of tumor aggressiveness in a variety of neoplasms (Kameyama et al., 1996; Demeure et al., 1992). The high frequency at 
which MMP3 are detected at mRNA and/or protein levels in invasive tumor cell lines and various human carcinomas suggests that MMPs are implicated in invasion and metastasis (Liotta et al., 1991; Tryggvason et al., 1993). Recent study showed that MMP9 were overexpressed in gastric tumours compared with normal tissue and it may act together to increase carcinogenesis and the progression, invasion and metastasis of gastric carcinoma (Yang et al., 2011). However, little studies reported the expression of other MMPs including MMP9 in PTC.

In the present study, we examined the expression levels of MMP9 in human PTC on mRNA level and protein level by quantitative reverse transcription-polymerase chain reaction (qRT-PCR) and immunohistochemistry, respectively. We also tested the correlations between the immunohistochemical scores and several clinicopathological parameters to find out the association between MMP9 and PTC.

\section{MATERIALS AND METHODS}

\section{Clinical samples and patients}

Fresh tissue samples of thyroid were obtained from patients with primary papillary carcinoma (66 cases), 20 cases of thyroid adenoma, 20 cases of multi-nodular goiters, and 10 cases of normal thyroid who underwent surgery in the Department of Thyroid Surgery at The First Affiliated Hospital of Jilin University between January and September, 2009 to March, 2011. The patients with PTC ranged in age from 19 to 68 years (mean \pm SD, $40.2 \pm 0.6$ years), which included 31 male (46.9\%) and 35 female (53.1\%), 37 patients were younger than 45 years and 29 patients were older than 45 years.

Diagnosis and staging of PTC was performed according to the Union Internationale Control Cancer (UICC) classification (TumorNode-Metastasis, 1992). Stages I and II were found in 40 (61\%) patients, and III and IV in $26(39 \%)$ patients. Surgical specimens were fixed with $10 \%$ buffered formalin, and paraffin sections were stained with Hematoxylin and eosin (H\&E). This study was approved by the ethics committee of Jilin hospital and an informed consent was obtained from all participants.

\section{qPCR}

Total RNA was isolated from frozen thyroid tissue using TRIZOL reagent (Invitrogen, USA) according to the manufacturer's protocol and as described in the online supplement. The purity and concentration of RNA were determined using a dual beam ultraviolet (UV) spectrophotometer (Eppendorf AG, Hamburg, Germany). Using mRNA as template, single-stranded cDNAs were generated by Superscript II reverse transcriptase (Invitrogen) according to the manufacturer's directions. The MMP9 primer sequences are as follows: Sense prime: 5'- TGGTGTGCCCTGGAACTCA-3'; Anti-sense prime: 5'- TGGTGTGCCCTGGAACTCA -3'.

The qPCR conditions are as follows: an initial $95^{\circ} \mathrm{C}$ for $3 \mathrm{~min}$ and followed by 40 cycles of $95^{\circ} \mathrm{C}$ for $15 \mathrm{~s}$ and $55^{\circ} \mathrm{C}$ for $1 \mathrm{~min}$. A dissociation curve was established after each PCR in order to verify amplification specificity. The integrity of the MMP9 and the efficiency of qPCR in each sample were confirmed by the endogenous control U6 small RNA. Negative control experiments were set without cDNA template. The relative quantification of each MMP9 was presented as the fold change after normalized to the U6 RNA for the Equation 2- $\Delta \Delta \mathrm{Ct}$ in the Rotor-Gene 6000 Series Software 1.7 (Qiagen), where $\Delta \mathrm{Ct}=(\mathrm{CtmiRNA}-\mathrm{CtU} 6)$. Expression of MMP9 in lesions was compared to the normal tissues using a formula:

$\Delta \Delta \mathrm{Ct}=(\mathrm{Ct}$ tumor MMP9 $-\mathrm{Ct}$ tumor U6) $-(\mathrm{Ct}$ normal MMP9 $-\mathrm{Ct}$ normal U6).

\section{Immunohistochemistry}

To detect expression and localization of MMP9 in thyroid tissue, immunohistochemical was performed using SP reagent kit (Tiangen, China) according to the manufacturer's protocol and as described in the online supplement.

The degree of immunoreactivity was assessed similarly to the system described by Campo et al. (1992). The intensity of the staining was graded as $1+, 2+$ or $3+$. In cases with variable staining intensities, the most common pattern was recorded. The extent of staining was considered as $1+$ if the number of reactive cells was less than $25 \%, 2+(25 \pm 75 \%$ reactive cells), and $3+$ (more than $75 \%$ ). Cases with 0 or $1+$ staining were classified as negative, and cases with $2+$ or $3+$ staining were classified as positive. The final score was obtained in each case by adding the intensity to the extent score. Immunoreactivity was then classified according to the combined score as weak (scores 1 and $2,+$ ), moderate (3 and 4, $++)$, or strong (5 and higher, +++$)$. All slides were scored independently by two observers (M.B.R. and O.Y.). Five cases with discordant results were reevaluated to obtain agreement.

\section{Statistics analysis}

To calculate the statistical differences between thyroid carcinomas and benign tumor, the statistical package SAS 6.12 (USA) was used for all analyses. Methods were Pearson Chi-square test and Pearson correlation analysis. Student's $t$-test was used to determine the significance of differences between the groups. All values were expressed as mean \pm SD. In general, $p$-values less than 0.05 were considered statistically significant.

\section{RESULTS}

\section{qRT-PCR analysis of mRNA expression of MMP9}

In order to detect the mRNA expression of MMP9 in patients with thyroid carcinoma, qPCR was conducted. As shown in Table1, MMP9 was significantly over-expressed in thyroid papillary cancers compared to the thyroid adenoma, normal thyroid tissues and multinodular goiters $(P<0.05)$ (Table 1). However, there was no significant difference among the thyroid adenoma, normal thyroid tissues and multinodular goiters (Table 1).

\section{Immunohistochemistry analysis protein expression of MMP9}

In order to further confirm MMP9 protein expression, immunohistochemistry was conducted. As shown in Figure 1, thyroid adenoma and multinodular goiters thyroid, 


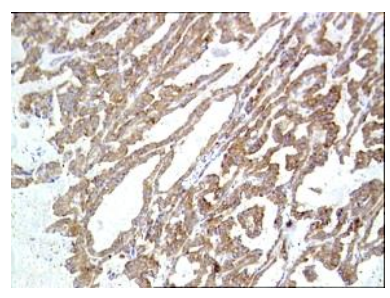

(A)

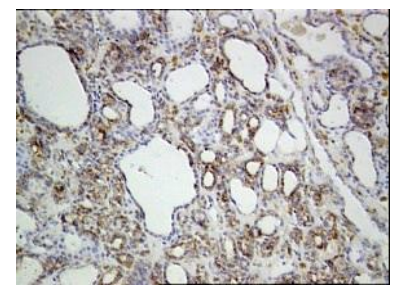

(B)

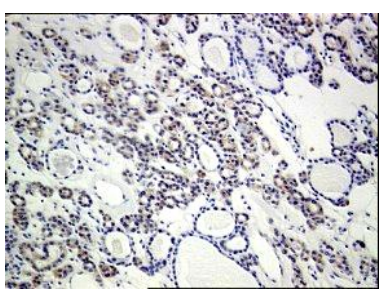

(C)

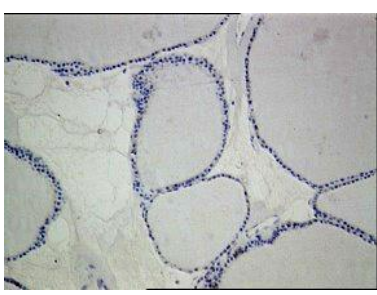

(D)

Figure 1. The expression of MMP9 protein by immunohistochemical staining at thyroid carcinoma tissue, thyroid adenoma, normal thyroid tissues and multinodular goiters tissue. A, Thyroid carcinoma tissue; B, thyroid adenoma; C, multinodular goiters; D, normal thyroid tissues.

Table 1. Expression of MMP9 mRNA in thyroid carcinoma tissue, thyroid adenoma, normal thyroid tissues and multinodular goiters.

\begin{tabular}{lcc}
\hline Group & $\mathbf{n}$ & $\bar{x} \pm \mathbf{s}($ copy/ug RNA) \\
\hline PTC & 66 & $577186.97 \pm 48354.25^{\mathrm{A}}$ \\
Normal tissue & 10 & $20428.14 \pm 143315.84^{\mathrm{B}}$ \\
Thyroid adenoma & 20 & $21976.98 \pm 167021.72^{\mathrm{B}}$ \\
Goiters & 20 & $23057.39 \pm 143315.68^{\mathrm{B}}$ \\
\hline
\end{tabular}

Different marks represent the significant difference at $p<0.05$.

tumor cells and stromal fibroblasts had little immunostained in any of the cases, Also, no staining was seen in the control normal samples. MMP9 was immunolocalized mainly to the carcinoma cells. Table 2 showed that there were significantly differences $(P<0.05)$. MMP9 expression between thyroid carcinoma and thyroid adenoma, and normal thyroid tissues and multinodular goiters $(P<0.05)$; MMP9 protein expression levels in thyroid carcinoma group were significantly up-regulate compared to other group $(P<0.05)$,

\section{Associations of clinical and pathological variable and MMP9 expression in PTC}

In this study, we analyzed the relationship between MMP9 protein expression and clinical and pathological variables, including gender, mean age, UICC stage and lymph node degree in PTC, using Pearson Chi-square $\left(x^{2}\right)$ test. We found significant associations between MMP9 protein expression and UICC stage, tumor size and lymph node metastasis $(P<0.05$, Table 3$)$. MMP9 up-expression was significantly associated with UICC stage $(P=0.006)$, being observed more frequently in cases Stages III to IV (100\%) than in cases Stages I to II $(87.75 \%)$. However, MMP9 protein expression had no significant associations with gender and age.
Table 2. Expression of MMP9 in thyroid carcinoma tissue, thyroid adenoma, normal thyroid tissues and multinodular goiters by immunohistochemical staining.

\begin{tabular}{lcccc}
\hline \multirow{2}{*}{ Group } & \multirow{n}{*}{$\mathbf{n}$} & \multicolumn{3}{c}{ MMP9 } \\
\cline { 3 - 5 } & & - & $\boldsymbol{+}$ & $(\%)$ \\
\hline PTC & 66 & 5 & 61 & 92.4 \\
Thyroid adenoma & 20 & 14 & 6 & 30.0 \\
Multinodular goiters & 20 & 18 & 2 & 10.0 \\
Normal tissue & 10 & 10 & 0 & 0 \\
\hline
\end{tabular}

\section{DISCUSSION}

In the present study, we chose to study the MMP9 gene and to assess its expression and association in different thyroid tissues. qPCR experiment verified that MMP9 production was increased on the mRNA level of thyroid carcinoma when compared to thyroid adenoma and normal thyroid tissues and multinodular goiters $(\mathrm{P}<$ $0.05)$, On protein level, MMP9 expression production in thyroid carcinoma group were significantly up-regulate compared to other group $(P<0.05)$ using immunohistochemistry. Furthermore, we identified significant associations between MMP9 protein expression and UICC stage and lymph node metastasis $(P<0.05)$. The current study provides important data on the involvement of MMP9 in the pathogenesis of thyroid carcinoma.

The current studies have demonstrated that the production level of MMP9 is remarkably higher in the carcinomas than in the non-carcinoma tissues. The enhanced production of MMP9 protein have been reported in many human carcinomas, including stomach (Nomura et al., 1996), breast (Ueno et al., 1997), lung (Tokuraku et al., 1995) and endometrial carcinomas (Yu et al., 2012). Moreover, some studies showed that the production levels of MMP9 in the carcinoma tissue are negligible due to unique of thyroid carcinomas (Nakamura et al., 1999), which did not comply with our results that the production level of MMP9 is remarkably 
Table 3. The associations between MMP9 expression and clinicopathological features of thyroid papillary cancers.

\begin{tabular}{|c|c|c|c|c|c|}
\hline \multirow{2}{*}{ Clinicopathological feature } & \multirow{2}{*}{$\mathbf{n}$} & \multicolumn{4}{|c|}{ MMP-9 } \\
\hline & & - & + & $x^{2}$ & P-value \\
\hline Thyroid adenoma & 20 & 14 & 6 & 1 vs $2: 38.969$ & 1 vs $2: 0.001$ \\
\hline Multinodular goiters & 20 & 18 & 2 & 1 vs $3: 51.802$ & 1 vs $3: 0.001$ \\
\hline Normal tissues & 10 & 10 & 0 & 2 vs 3:3.805 & 2 vs 3:0.05 \\
\hline PTC & 66 & 5 & 61 & & \\
\hline \multicolumn{6}{|l|}{ Lymph nodes } \\
\hline No & 12 & 2 & 10 & \multirow{2}{*}{1.906} & \multirow{2}{*}{0.167} \\
\hline Yes & 54 & 3 & 51 & & \\
\hline \multicolumn{6}{|l|}{ Tumor size (cm) } \\
\hline$\leq 1.0$ & 17 & 3 & 14 & \multirow{2}{*}{11.553} & \multirow{2}{*}{0.001} \\
\hline$>1.0$ & 49 & 2 & 47 & & \\
\hline \multicolumn{6}{|l|}{ UICC stage } \\
\hline I - || & 40 & 5 & 35 & \multirow{2}{*}{7.470} & \multirow{2}{*}{0.006} \\
\hline III - IV & 26 & 0 & 26 & & \\
\hline \multicolumn{6}{|l|}{ Gender } \\
\hline Male & 31 & 1 & 30 & \multirow{2}{*}{1.826} & \multirow{2}{*}{0.177} \\
\hline Female & 35 & 4 & 31 & & \\
\hline \multicolumn{6}{|l|}{ Age } \\
\hline$<45$ & 37 & 5 & 32 & \multirow{2}{*}{0.076} & \multirow{2}{*}{0.003} \\
\hline$\geq 45$ & 29 & 0 & 29 & & \\
\hline
\end{tabular}

increased in thyroid carcinomas; the reason might be that tissue sample of thyroid carcinomas was different form our study or that study method was different from our method. In this study, we collected enough sample, mRNA level and protein level was studied by qPCR and immunohistochemistry, respectively, therefore, our result might be more reasonable and concise.

In conclusion, the present study demonstrated that MMP9 expression was significantly up-regulated in thyroid carcinoma tissue in comparison to the thyroid adenoma and normal thyroid tissues and multinodular goiters $(P<0.05)$. These results implied that MMPs play a key role in tumor invasion and metastasis, and suggested that increased MMP9 expression might be a useful diagnostic marker and might also become a potential target in the treatment of thyroid carcinoma.

\section{ACKNOWLEDGEMENT}

The authors gratefully acknowledge the financial support provided by Health Bureau of Jilin (2008Z017).

\section{REFERENCES}

Brown RL, de Souza JA, Cohen EE (2011). Thyroid cancer: burden of illness and management of disease. J. Cancer. 2:193-199.

Campo E, Merino MJ, Liotta L, Neuman R, Stetler Stevenson W (1992). Distribution of 72KD type IV collagenase in nonneoplastic and neoplastic thyroid tissue. Hum. Pathol. 23:1395-1401.

Chambers AF, Matrisian LM (1997). Changing views of the role of matrix metalloproteinases in metastasis. J. Natl. Cancer. Inst. 89:1260-1270.

Curran S, Murray G (1999). Matrix metalloproteinases in tumor invasion and metastasis. J. Pathol. 189:300-308.

Dal Maso L, Bosetti C, La Vecchia C, Franceschi S (2009). Risk factors for thyroid cancer: an epidemiological review focused on nutritional factors. Cancer .Causes. Control 20:75-86.

Demeure MJ, Damasky CH, Elfman F, Goretzki PE, Wong MG, Clark $\mathrm{OH}$ (1992). Invasion by culture human follicular thyroid cancer correlates with increased b1 integrins and production of proteases. World J .Surg. 16:770-776.

Guang C, Meishan J, Shan L (2011). Increased expression cysteinerich61 (Cyr61) in patients with thyroid carcinomas Afr. J. Pharm. Pharmacol. 5(22):2517-2521.

Hagemann C, Anacker J, Ernestus RI, Vince GH (2012). A complete compilation of matrix metalloproteinase expression in human malignant gliomas. World J. Clin. Oncol. 23(5):67-79.

Hundahl SA, Cady B, Cunningham MP, Mazzaferri E, McKee RF, Rosai J, Shah JP, Fremgen AM, Stewart AK (2000). Initial results from a 
prospective cohort study of 5583 cases of thyroid carcinoma treated in the United States during 1996. U.S. and German Thyroid Cancer Study Group. An American College of Surgeons Commission on Cancer Patient Care Evaluation study. Cancer 89:202-217.

Kameyama K (1996). Expression of MMP-1 in the capsule of thyroid cancer relationship with invasiveness. Pathol. Res. Pract. 192:20-26.

Liotta LA, Steeg PS. Stetler-Stevenson WG (1991). Cancer metastasis and angiogenesis: an imbalance of positive and negative regulation. Cell 64:327-336.

Nakamura H, Ueno H, Yamashita K, Shimada T, Yamamoto E, Noguchi M, Fujimoto N, Sato H, Seiki M, Okada Y (1999). Enhanced Production and Activation of Progelatinase A Mediated by MembraneType 1 Matrix Metalloproteinase in Human Papillary Thyroid Carcinomas. Cancer Res. 15(2):467-473.

Nomura H, Fujimoto N, Seiki M, Mai M, Okada Y (1996). Enhanced production of matrix metalloproteinases and activation of matrix metalloproteinase 2 (gelatinase A) in human gastric carcinomas. Int. J. Cancer 69:9-16.

Parson SL, Watson SA, Brown PD, Collins HM, Steele RJ (1997). Matrix metalloproteinases. Br. J. Surg. 84:160-166.

Roskies M, Dolev Y, Caglar D, Hier MP, Mlynarek A, Majdan A, Payne RJ (2012). Vitamin D deficiency as a potentially modifiable risk factor for thyroid cancer. J. Otolaryngol. Head Neck Surg. 41(3):160-163

Salamonsen LA (1996). Matrix metalloproteinases and their tissue inhibitors in endocrinology. Trend Endocrinol. Metab. 7:28-43.
Tokuraku M, Sato H, Murakami S, Okada Y, Seiki M (1995). Activation of the precursor of gelatinase A/72 $\mathrm{kDa}$ type IV collagenase/MMP-2 in lung carcinomas correlates with the expression of membrane-type matrix metalloproteinase (MT-MMP) and with lymphnode metastasis. Int. J. Cancer 64:355-359.

Tryggvason K, Hoyhtya M, Pyke C (1993). Type IV collagenases in invasive tumors. Breast Cancer Res. Treat. 24:209-218.

Ueno H, Nakamura H, Inoue M, Imai K (1997). Expression and tissue localization of membrane-types 1,2 , and 3 matrix metalloproteinases in human invasive breast carcinomas. Cancer. Res. 57:2055-2060.

Westermarck J, Kahari VM (1999). Regulation of matrix metalloproteinase expression in tumor invasion. J. FASEB. 13:781791.

Yang S, Zhao Z, Wu R, Lu H, Zhang X, Huan C, Wang C, Wu X, Guan $G(2011)$.Expression and biological relationship of vascular endothelial growth factor-A and matrix metalloproteinase- 9 in gastric carcinoma. J. Int. Med. Res. 39(6):2076-85.

Yu F, Jiang Q, Zhou Y, Yang Z, Yu X, Wang H, Liu Z, Wang L, Fang W, Guo $S$ (2012). Abnormal expression of matrix metalloproteinase- 9 (MMP9) correlates with clinical course in Chinese patients with endometrial cancer. Dis. Markers 32(5):321-327. 